\title{
Interaction between periodontitis and liver diseases (Review)
}

\author{
PENGYU HAN ${ }^{1}$, DIANXING SUN ${ }^{1}$ and JIE YANG $^{2}$ \\ ${ }^{1}$ The Liver Disease Diagnosis and Treatment Center of PLA, Bethune International Peace Hospital, Shijiazhuang, \\ Hebei 050082; ${ }^{2}$ Department of Public Healthcare, Hebei Medical University, Shijiazhuang, Hebei 050017, P.R. China
}

Received March 15, 2016; Accepted June 9, 2016

DOI: $10.3892 /$ br.2016.718

\begin{abstract}
Periodontitis is an oral disease that is highly prevalent worldwide, with a prevalence of $30-50 \%$ of the population in developed countries, but only $\sim 10 \%$ present with severe forms. It is also estimated that periodontitis results in worldwide productivity losses amounting to $\sim 54$ billion USD yearly. In addition to the damage it causes to oral health, periodontitis also affects other types of disease. Numerous studies have confirmed the association between periodontitis and systemic diseases, such as diabetes, respiratory disease, osteoporosis and cardiovascular disease. Increasing evidence also indicated that periodontitis may participate in the progression of liver diseases, such as non-alcoholic fatty liver disease, cirrhosis and hepatocellular carcinoma, as well as affecting liver transplantation. However, to the best of our knowledge, there are currently no reviews elaborating upon the possible links between periodontitis and liver diseases. Therefore, the current review summarizes the human trials and animal

Correspondence to: Professor Dianxing Sun, The Liver Disease Diagnosis and Treatment Center of PLA, Bethune International Peace Hospital, 398 West Zhongshan Road, Shijiazhuang, Hebei 050082, P.R. China

E-mail: sundianxing@hotmail.com
\end{abstract}

Abbreviations: MS, metabolic syndrome; CVD, cardiovascular disease; NAFLD, non-alcoholic fatty liver disease; NAFL, non-alcoholic fatty liver; NASH, non-alcoholic steatohepatitis; ALT, alanine aminotransferase; GGT, $\gamma$-glutamyl transferase; LC, liver cirrhosis; HCC, hepatocellular carcinoma; HBV, hepatitis B virus; HCV hepatitis C virus; JIS, Japan integrated staging; TNM, tumor node metastasis; ROM, reactive oxygen metabolites; LT, liver transplantation; MELD, model for end-stage liver disease; DM, diabetes mellitus; INF, interferon; TLR, Toll-like receptor; AST, aspartate transaminase; TNF, tumor necrosis factor; CD, cluster of differentiation; HSPs, heat shock proteins; ROS, reactive oxygen species; RNS, reactive nitrogen species; MDA, malondialdehyde; GCF, gingival crevicular fluid; LPS-PG, lipopolysaccharide from Porphyromonas gingivalis; PDL, periodontal ligament; NOX, NADPH oxidase; NADPH, nicotinamide adenine dinucleotide phosphate

Key words: non-alcoholic fatty liver disease, periodontitis, cirrhosis, hepatocellular carcinoma, liver transplantation, bacteria experiments that have been conducted to investigate the correlation between periodontitis and liver diseases. Furthermore, in the present review, certain mechanisms that have been postulated to be responsible for the role of periodontitis in liver diseases (such as bacteria, pro-inflammatory mediators and oxidative stress) are considered. The aim of the review is to introduce the hypothesis that periodontitis may be important in the progression of liver disease, thus providing dentists and physicians with an improved understanding of this issue.

\section{Contents}

1. Introduction

2. Associations between systemic diseases and periodontitis

3. Periodontitis and liver diseases

4. Mechanisms of periodontitis on LD

5. Pro-inflammatory mediators

6. Oxidative stress

7. Hypothesis

\section{Introduction}

Periodontal diseases, which include gingivitis (where the inflammation is confined to the gingiva and is reversible with dental care) and periodontitis (where the inflammation spreads, and results in tissue destruction and alveolar bone resorption), are the most common types of disease in humans worldwide (1). Tissue destruction, such as the breakdown of the collagen fibres of the periodontal ligament (PDL) and the loss of gingival tissue and alveolar bone, are characteristic of periodontitis, resulting in gradual weakening of the tooth-supporting tissues, which eventually leads to tooth loss. The condition is widespread. Severe periodontitis that threatens tooth retention affects $10-15 \%$ of adults in the majority of populations investigated and ranged from $1 \%$, among 20- to 29-year-old, to $39 \%$, among individuals $>65$-year-old while moderate periodontitis affects $40-60 \%$ of adults in all populations (2). Therefore, periodontitis is a highly prevalent, chronic inflammatory disease, which has negative and profound impacts on many aspects of daily life (3).

\section{Associations between systemic diseases and periodontitis}

Periodontitis has been a controversial point of interest due to the identification of correlations between it and metabolic 
syndrome (MS). MS is a condition, which constitutes a group of risk factors that occur together and increase the risk for coronary artery disease, stroke and type 2 diabetes mellitus (DM) (4).

Important investigations into the underlying mechanisms linking periodontitis to systemic disorders have ensued, resulting in the development of a novel branch of periodontics termed 'periodontal medicine' (5). Since the first report of the association between periodontitis and systematic diseases, there have been constant novel discoveries. Along with five other complications (diabetic cardio-cerebrovascular disease, diabetic nephropathy, diabetic eye disease, diabetic neuropathy and diabetic sexual dysfunction) periodontal disease has been labeled as the sixth complication of diabetes (6). Thus, periodontitis and diabetes appear to interact. Clinical evidence provides strong support to the statement that periodontal infection contributes to the worsening of glycaemic control in individuals with diabetes (7). Respiratory disease and chronic obstructive pulmonary disease are other systemic disorders ranking the third and sixth most common causes of mortality worldwide in 1990, causing 4.3 and 2.2 million mortalities, respectively (8) and a cross-sectional study suggested that chronic obstructive pulmonary disease may be associated with severe periodontitis (2). The teeth and periodontium may serve as a reservoir for respiratory infection (9), and dental plaque maybe the important local source of the anaerobic bacteria, which cause pneumonia or other types of respiratory infection. Several mechanisms have been proposed to explain the mechanism by which oral bacteria participate in the pathogenesis of respiratory infection, including orally inhaled periodontal bacteria, periodontal disease-associated enzymes and cytokines (10). Cardiovascular disease (CVD) accounts for $29 \%$ of mortalities worldwide, ranking the second leading cause of mortality following infectious and parasitic disease (11). Until now, numerous studies that were based upon the inflammation hypothesis of CVD, considered periodontal diseases to be infection-triggered inflammatory diseases (12). Furthermore, various epidemiology experiments that have been conducted over the years have suggested a positive association between periodontal diseases and CVD (12). Characterized by an imbalance between bone formation and bone resorption, osteoporosis is the most common type of metabolic bone disease; periodontitis and osteoporosis share similar traits with regard to bone resorption (13). Although substantiated studies attempting to demonstrate the positive correlation between periodontal disease and osteoporosis have been performed, the majority of the studies are uncontrolled and cross-sectional in design (14); therefore, in order to elucidate the associations between these two diseases, further prospective studies are required.

\section{Periodontitis and liver diseases}

Non-alcoholic fatty liver disease (NAFLD). Approximately one-quarter of the entire adult population in the world shows excessive hepatic fat accumulation, and NAFLD is the most common form of chronic liver disease encountered in developed countries (15). The prevalence of NAFLD throughout the world is speculated to be $20-30 \%$ (16), among obese patients the figure rises to $57-74 \%$ (17). NAFLD represents a wide spectrum of conditions, ranging from NAFL to non-alcoholic steatohepatitis (NASH) $(15,18)$. The diagnosis of NAFLD is often established following identification of elevated serum alanine aminotransferase (ALT) and $\gamma$-glutamyl transferase (GGT), which is most commonly used for screening of liver diseases in obese and asymptomatic patients $(19,20)$.

Interactions between NAFLD and periodontitis. Thus far, a small number of studies have been conducted to identify the association between NAFLD and periodontitis, the majority of which have been performed in Japan. In a study conducted in a Japanese college, male students with a high level of serum ALT were identified to be significantly more likely to have periodontitis than those with a low level of serum ALT (21). As for females, the association between a higher ALT level and an increased risk of periodontitis was not found to be significant, which was in contrast to a previous study that indicated that the incidence rate of periodontitis in females aged 20-59 years was significantly increased with elevated serum levels of ALT (22). The author of the above-mentioned studies attributed this discrepancy to the differences in the age of the subjects and the sample size. Notably, it seems that the association between periodontitis and the serum levels of ALT is mutual. In a cross-sectional study with a large sample size that was conducted in Japan, researchers found that ALT and GGT levels were higher in patients with periodontal pockets(depth, $\geq 4 \mathrm{~mm}$ ) when compared to healthy controls. Multiple logistic regression analysis with GGT or ALT as the dependent variable revealed that there was a significant association between periodontal pockets and GGT, even after adjusting for age, gender, cigarette smoking, alcohol drinking habits, and symptoms of MS (23). In a previous study, it was found that periodontal treatments improved certain liver function parameters, such as serum aspartate transaminase and ALT in NAFLD patients (24). Such periodontal treatments include oral hygiene procedures, including scaling, root planing procedures and application of minocycline hydrochloride.

Liver cirrhosis $(L C)$. LC is a major, life-threatening health problem worldwide. LC is often a result of liver injuries of numerous different etiologies, leading to hepatocyte damage, hepatic inflammation and fibrogenesis (25). Furthermore, LC can lead to the development of hepatocellular carcinoma (HCC) (26). LC is histologically characterized by increased deposition in, and altered composition of, the extracellular matrix and the appearance of regenerative nodules. The destruction of the normal architecture of the liver and the loss of its functional hepatocytes prevent the liver from performing its normal detoxification, synthesis, and metabolic functions, eventually leading to portal hypertension and liver failure. From a clinical standpoint, LC is regarded as an end-stage disease, which results in mortality, unless a liver transplantation (LT) is performed (27).

Interaction between periodontitis and $L C$. The association between LC and periodontal disease has been evaluated in previous studies. In one study, researchers identified that patients with non-alcoholic cirrhosis exhibited a tendency to have a larger clinical attachment loss (CAL) when compared with healthy volunteers, although no significant difference 
was found within any of the age groups. Notably, significant differences between healthy controls and patients with alcoholic cirrhosis were found in each age group (28). It has also been shown that patients with cirrhosis exhibited a worse periodontal status compared with healthy control individuals (29). Furthermore, studies found that patients who had suffered with cirrhosis for $>3$ years exhibited greater CAL, dental plaque and calculus when compared to patients with $<3$ years cirrhosis (30). The effects on periodontal health, which are brought about by LC may be due to decreased blood flow of the mucogingival junction (31) and increased levels of serum alkaline phosphatase (32). Thus far, the effect of periodontitis on LC has not been fully investigated. Therefore, more studies are required to better understand the link between these two diseases.

HCC. HCC is the sixth most common type of cancer and accounts for $\sim 9.2 \%$ of all cancer-associated mortalities (33). $\mathrm{HCC}$ is more common in males than in females and predominantly occurs in developing countries. The increasing trend is primarily due to a cohort effect associated with the hepatitis B and C viruses (HBV and HCV), the incidence of which peaked between the 1950s and 1980s (33). By contrast, in North America, Europe and Japan, the HCV infection is the main risk factor, together with alcohol abuse (33). Time trends of incidence of HCC in developed countries correspond tot he timing of HCV spread. In Japan and Europe, where the $\mathrm{HCV}$ infection spread earlier than in the USA, the incidence of HCC has almost reached a plateau and is declining in certain areas; however, in the USA, the incidence continues to increase and the infection may have a synergistic effect with other risk factors, such as NAFLD. In the majority cases, HCC is a multistage disease, the occurrence of which is linked to environmental, dietary and lifestyle factors (34). Unlike other types of cancer, HCC usually arises on a previously damaged organ, primarily in the setting of chronic hepatopathy, cirrhosis $(35,36)$, or in association with hereditary diseases, such as hemochromatosis, Wilson's disease and a-1-antitrypsin deficiency (34). However, in $~ 15-20 \%$ of cases HCC may occur in the non-fibrotic liver or in livers with minimal portal fibrosis without any septal fibrosis (37).

Interaction between periodontitis and HCC. A number of studies have demonstrated the association between periodontitis and cancer. An epidemiological study reported a positive association between periodontitis and lung cancer mortality, in addition to other established risk factors for lung cancer (38). A cross-sectional study demonstrated that the loss of alveolar bone is considered an increased risk factor of tongue cancer (39). Furthermore, a hospital-based case-control study demonstrated that patients presenting with periodontitis were more likely to have poorly differentiated squamous cell carcinoma in the oral cavity compared with those individuals without periodontitis (40). Based on this evidence, novel discoveries were made regarding the link between periodontitis and HCC.

In a Japanese study, it was found that the stage of HCC is associated with periodontitis. A method called the Japan Integrated Staging (JIS) system (41) was applied to assess the severity of HCC. The JIS system, which is accepted by many institutions in Japan because of its simplicity and validity $(41,42)$, is based on a combination of the Child-Pugh score (43) and the tumor node metastasis (TNM) classification. The study demonstrated that HCC patients with chronic periodontitis had greater JIS scores and higher serum levels of total bilirubin when compared with the patients who had good periodontal and gingival health. Furthermore, a backward stepwise logistic regression model confirmed that progression of the JIS score was significantly associated with probing pocket depth. Increased serum levels of reactive oxygen metabolites (ROM) were also seen in HCC patients with chronic periodontitis when compared to those exhibiting good periodontal and gingival health (44).

LT. LT is a treatment for HCC, which was first performed in the late 80 s and early 90s (45). Early studies indicated a poor outcome with regards to survival rates and high tumor recurrence $(46,47)$. This was predominantly due to the fact that there were no standard criteria for selecting patients for LT (48). In 1996, a landmark study resulted in the development of enrolling criteria, commonly known as the Milan Criteria (49), which is designed to selectively enroll patients for LT and reduce the risk of mortality. Currently, LT is considered to be the best treatment option for HCC and cirrhosis for patients who fulfill the eligibility criteria.

Interaction between periodontitis and LT. Various traits of periodontitis are associated with LT. Periodontitis-induced immunosuppression may encourage infections following LT. Therefore, an oral examination has long been a requirement prior to LT with the aim of eliminating oral foci of infection and, hence, preventing sepsis of oral origin (50-55).

A pilot study, which recruited 16 patients with end-stage liver disease and 16 control subjects with no liver diseases, showed that the end-stage liver disease patients exhibited a higher incidence of oral manifestations when compared with the control group, and had at least one oral disease or abnormality, which required dental treatment prior to LT (56). A study conducted in Finland, where 116 adult patients with a primary diagnosis of LC and who were due to undergo LT were examined. The study found that the number of tooth extractions, a surrogate marker of dental infections, was associated with a significantly reduced time required from the diagnosis of LD to LT. This association remained significant following adjustment for age, gender, LD etiology and the model for end-stage liver disease (MELD) score; additionally, alcoholic cirrhosis was the only other significant factor in the multivariate analysis (57). Another similar study, also conducted in Finland, confirmed that a lower MELD score was associated with fewer tooth extractions (58). Furthermore, the LT candidates with an end-stage liver disease and the highest MELD score usually exhibited various medical complications, such as severe ascites, malnutrition, variceal bleeding and infections (58). Premedications, such as antibiotic prophylaxis and coagulating agents, are often used to reduce the complications associated with dental treatments of patients with a severe LD, thus compromising the patients and rendering them at very high risk for dental treatment complications (59-62). Another study conducted in Brazil also showed that treating oral lesions, such as periodontitis 
before and after LT, seemed to result in reduced mortality (63). Unfortunately, despite the important role played by periodontal health in LT, those patients who are on the transplantation waiting list tend to neglect their oral health resulting in poorer oral statuses than the general population $(64,65)$.

\section{Mechanisms of periodontitis on $\mathrm{LD}$}

Effects of bacteria on $L D$. The microbial etiology of periodontal disease has been the focus of research for a long time. Approximately 400 species have been detected in the gingival sulcus, among them are Porphyromonas gingivalis ( $P$. gingivalis) and Tannerella forsythia, which are widely regarded as major pathogens in periodontitis (66). Subgingival microbiota were classified into several complexes indicated by various colors; the colors (varying from red to yellow) have different connotations, with red being the most pathogenic and yellow being less invasive. Periodontal microbiota are more heterogeneous than earlier believed. In dentistry, gram-negative organisms were considered to be the predominant bacteria in periodontitis; however, gram-positive organisms found in deep, diseased sites are proposed to be the most important pathogens in periodontitis (67). Bacteria also have a negative effect on the liver. It is well known that patients with cirrhosis are at greater risk of bacterial infection $(68,69)$ and infections rate is 4 - to 5 -fold higher than the general population $(70,71)$. It is also reported that spontaneous bacterial peritonitis (SBP) is one of the most encountered infectious complications by patients with cirrhosis on the LT list (72). Thus, the present review evaluated a selection of the most studied bacteria that are associated with LD.

$P$. gingivalis. $P$. gingivalisis a gram-negative oral anaerobe, which is a major cause of periodontitis. It participates in severe forms of periodontitis, and it is a prominent component of the oral microbiome and a successful colonizer of the oral epithelium (73). A series of reports over the years suggest that infection with $P$. gingivalis is associated with several systemic diseases, including CVDs, preterm births, low birth weight, rheumatoid arthritis, and DM (74,75).

$P$. gingivalis is released from the sulcus into the bloodstream. Human trials and animal experiments have confirmed the presence of $P$. gingivalis in liver tissues $(76,77)$. Furthermore, the periapical granuloma, which served as a persistent and sustainable supply source of the $P$. gingivalis and its products, may lead to chronic liver injury (77). In a study where the incidence rate of $P$. gingivalis was compared between NAFLD patients and non-NAFLD control subjects, it was found that the detection frequency of the $P$. gingivalis infection in NAFLD patients was significantly higher (24). Notably, the detection frequency of $P$. gingivalis in the patients with NASH was also markedly higher than that of the non-NAFLD control subjects. In the same study, increased body and liver weights, accumulation of lipids in the liver, and increases in ALT and triglyceride (TG) levels were observed in high fat diet-induced steatosis mice that had received a direct injection of $P$. gingivalis (24). Animal experiments have also shown that dental infection of $P$. gingivalis may exacerbate the pathological progression of NASH from simple steatohepatitis to steatohepatitis with fibrosis (77). These results indicate that the presence of the
$P$. gingivalis infection maybe an independent predictor for the development of NAFLD and may contribute to the progression of other LD.

Aggregatibacter actinomycetemcomitans (A. actinomycetemcomitans). A. actinomycetemcomitans is an exogenous bacterium, which is associated with periodontitis in young individuals and has the ability to produce virulence factors (78). Studies have shown that A. actinomycetemcomitans generates certain products, which may inactivate and evade immune defense. The most investigated products of A. actinomycetemcomitans are leukotoxin and repeats in toxin (79). A previous study showed that the injection of A. actinomycetemcomitans into mice induced immunosuppression and suppressed the IgG response to red blood cells (80). The administration of A. actinomycetemcomitans has also been reported to induce systemic inflammation in apolipoprotein E-deficient mice (81). In an animal study, A. actinomycetemcomitans was present in liver tissue after intravenously inoculating mice with live A. actinomycetemcomitans. and may have induced moderate hepatic inflammation. The A. actinomycetemcomitans infection displayed more severe inflammatory changes in the liver, which positively correlated with serum markers of inflammation, such as interleukin (IL)-1 $\beta$, IL-12, IL-10, IL-6, tumor necrosis factor- $\alpha$ (TNF- $\alpha)$ and interferon- $\gamma($ INF- $\gamma)(82)$.

Periodontal bacteria and gut-liver axis malfunction. Numerous studies have demonstrated that gut-derived bacteria may contribute to the progression of LD (83-86). Although these studies focused on gut bacteria, it is hypothesized that these gastrointestinal bacteria may pass through the oral cavity and that certain bacteria may have arisen from the oral cavity. An animal study demonstrated that gut microbiota promoted absorption of monosaccharides in mice, which resulted in lipogenesis, and the bacteria responsible for this effect in mice were within the Firmicutes phylum. Additionally, Selenomonasnoxia, a gram-negative bacteria, which is found in the mouth and the gastro-intestinal tract, and participates in rapidly progressive periodontitis, was the only Firmicute that was significantly elevated in saliva (87). It has been estimated that $\sim 1$ gram of bacteria $\left(10^{11}\right.$ cells $)$ is swallowed with $500-1,500 \mathrm{ml}$ saliva each day (88). If the levels of S. noxia are $>1.05 \%$, this represents $\sim 10^{9}$ cells swallowed per day. It is therefore plausible that salivary microbiology would affect the formation of bacteria in the gastro-intestinal tract (89). The swallowed saliva of patients with periodontitis is reported to contain $\sim 10^{9}$ bacteria/ml, in 1.0-1.5 litres per day, resulting in a total of $>10^{12}$ bacteria per day (90-92). As the bacterial flora of the oral cavity is distinct from that of the gut (93), it is possible that swallowed bacteria may affect the composition of the gut microflora. Notably, it has been reported that oral probiotic intervention alters gut bacterial composition (94). Thus, orally-originating bacteria may be significant in gut-liver axis malfunction and the link between the two requires further investigation.

\section{Pro-inflammatory mediators}

Inflammatory mediators, such as IL-12/23, TNF- $\alpha$, and IL-1 may lead to the recruitment of activated neutrophils, which 
causes hepatocyte and vascular endothelial cell injuries by releasing oxidants and proteases $(95,96)$. Human trials $(97-105)$ and animal experiments (106-108) have confirmed the production of pro-inflammatory molecules in vivo and ex vivo in patients and animals with cirrhosis. The liver acts as the body's first defence against bacteria and microbial components. These pathogens, such as inflammatory mediators, which are present in the portal blood, generate the initial immunological and hormonal burden to the liver (109). Increasing evidence indicates that periodontitis-induced pro-inflammatory mediators may contribute to this burden.

Cytokines and chemokines. The dental plaque, partly composed of gram-negative bacteria cell walls, which are formed of peptidoglycans, polysaccharides, proteins, lipids, lipopolysaccharides (LPSs) and lipoproteins (110), commonly exist in the oral cavity of humans, particularly in those who suffer from periodontitis. Stimulated by these components, the periodontal tissue produces inflammatory cytokines (such as IL-1 $\beta$, IL-12, IL-10, IL-6, TNF- $\alpha$ and INF- $\gamma$ ) and chemokines [such as monocyte chemotactic protein 5 (MCP-5), IL-8 and macrophage inflammatory protein-1 $\alpha$ (MIP-1 $\alpha)$, prostaglandin E2 and nitric oxide (NO)] $(111,112)$. These pro-inflammatory cytokines are involved in the progression of LD, such as cirrhosis $(69,113-115)$. Oral bacteria are also important in the cytokine network. LPSs, released by periodontal bacteria, such as $A$. actinomycetemcomitans and $P$. gingivalis, affect the immune system by binding to Toll-like receptor (TLR)- 4 or -2 , oral bacteria also stimulate the expression of co-stimulatory molecules, cluster of differentiation (CD) 80/CD86 by binding to TLR4; and may participate in the activation of T-cells and exacerbate liver inflammation $(116,117)$. Kupffer cells, which express the highest levels of TLR4 in the liver, are the primary cells in liver inflammation that respond to LPSs in order to produce inflammatory cytokines, chemokines and reactive oxygen species (ROS) (117-119). In a previous animal study, it was confirmed that the administration of LPS generates changes in Kupffer cell function and increases liver parenchymal sensitivity to TNF- $\alpha$ in genetically obese mice (120). Additional animal experiments demonstrated that LPSs-induced TNF- $\alpha$ and its subsequent interaction with TLR2 signaling promoted NASH in mice $(120,121)$.

Peptidoglycans. The peptidoglycans, components of the bacterial walls (110), of circulating oral bacteria may stimulate blood cells to produce cytokines. As with LPS, peptidoglycans contribute to the activation of immune cells by binding to the TLR2 receptor (122). Furthermore, peptidoglycans can be recognized by the complement system and specific receptors, thus resulting in the production of TNF- $\alpha$, IL-6, IL- 8 , IL-1 $\beta$, MIP- $1 \alpha$ and NO in macrophages (123-125). It has also been shown that the levels of IL-6 specifically increased significantly following scaling (a dental practice often used to eliminate calculus), while the IL-8 levels decreased (126). Furthermore, studies have identified that patients with periodontitis exhibit higher levels of IL-6 in the sera when compared with healthy controls (127). The pro-inflammatory properties of peptidoglycans are different to those of LPSs, as the ligand of nucleotide binding oligomerization domain containing 2 is not a lipopolysaccharide, but a peptidoglycans $(128,129)$.
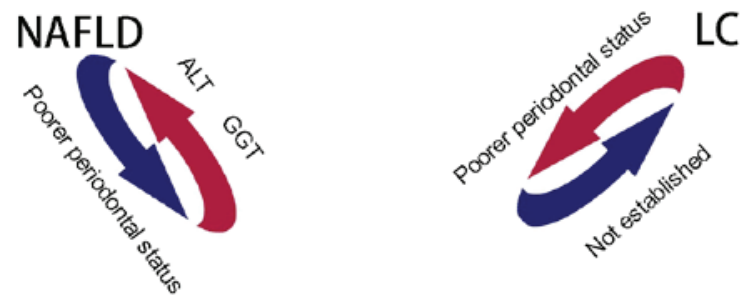

\section{Periodontitis}
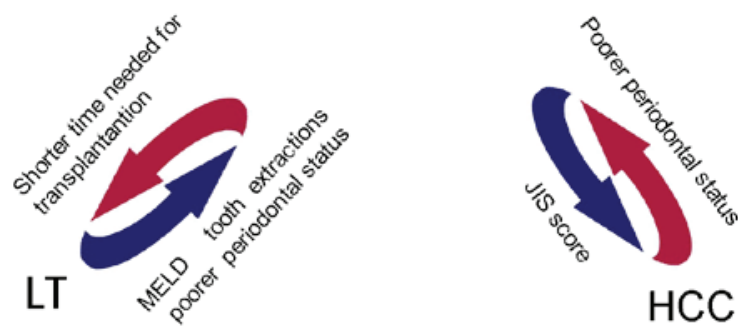

Figure 1. Periodontitis and liver disease. Periodontitis elevates ALT and GGT levels in patients with NAFLD. LC patients exhibit greater clinical attachment loss while the possible effect of periodontitis on LC has not, to the best of our knowledge, been established. HCC patients with periodontitis are associated with higher JIS scores than those with a healthy periodontal status. LT patients with periodontitis require LT after a shorter period and have a lower MELD score resulting in fewer tooth extractions. NAFLD, LC, HCC, and LT patients have poorer periodontal status than general population. ALT, alanine transaminase; GGT, $\gamma$-glutamyl transferase; NAFLD, non-alcoholic fatty liver disease; LC, liver cirrhosis; HCC, hepatocellular carcinoma; JIS, Japan integrated staging; LT, liver transplantation; MELD, Model for End-Stage Liver Disease.

Heat shock proteins (HSPs). HSPs are believed to be the most immunogenic antigens produced by bacteria. The extensive homology that exists between human and bacterial HSPs indicates that HSPs may have a role in the progression of hepatitis. A previous study showed that patients with periodontitis exhibited decreased proliferative responses of peripheral blood cells to HSP when compared to control patients (130). Additionally, antibodies against human HSP60 and $P$. gingivalis GroEL were observed in the sera and inflamed gingival tissues of patients with periodontitis (131). Animal experiments demonstrated that bacterial infection may lead to elevated production of antibodies that target HSP60 (which is expressed in the endothelium of blood vessels at their bifurcation stressed area). The mechanism of antibodies binding to the surface of the endothelium may be a triggering process associated with inflammatory autoimmune disease (132). Analysis of the nucleotide sequences of the T-cell receptor in periodontitis lesions showed that human HSP60-reactive T-cell clones and T-cells share the same receptors. The cytokine profile analysis showed that HSP60-reactive peripheral blood mononuclear cells produced a significant quantity of IFN- $\gamma$ in patients with periodontitis, and it is plausible that patients with periodontitis possess human HSP60-reactive T-cells with a type 1 cytokine profile (133).

\section{Oxidative stress}

Oxidative stress is an imbalance between the production and elimination of ROS, reactive nitrogen species (RNS) and free radicals, which causes DNA fragmentation, lipid peroxidation, 


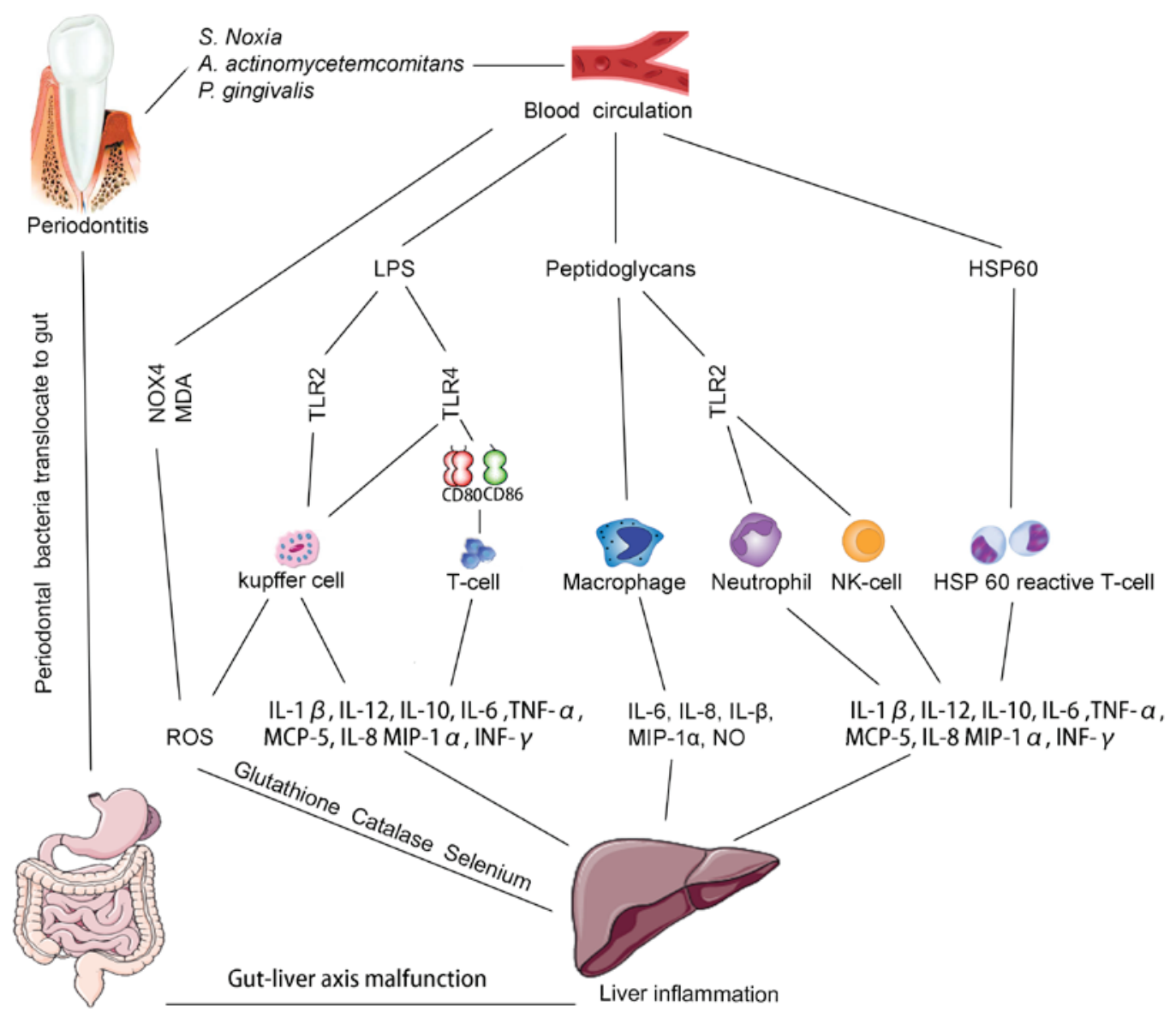

Figure 2. Role of periodontitis in liver inflammation. During periodontitis, periodontal tissue produces inflammatory cytokines and those inflammatory cytokines, along with other periodontal pathogens (such as periodontal bacteria and their components) translocate to the liver via blood circulation. LPSs released by periodontal bacteria stimulate Kupffer cells to generate cytokines by binding to TLR4 and TLR2, LPSs also stimulate the expression of co-stimulatory molecules CD80/CD86 by binding to TLR4. In addition, LPSs activate T-cells to generate cytokines. Peptidoglycans stimulate macrophages to generate cytokines, by recognizing specific receptors, and activate immune cells by binding to TLR2 receptors. Periodontitis-induced HSP60 stimulates T-cells to generate pro-inflammatory mediators. Periodontitis raises NOX4 and MDA, and lowers glutathione, catalase and selenium levels, which leads to the upregulation of ROS. The periodontal bacteria that translocates to the gut alters the gut microflora and contributes to gut-liver axis malfunction. LPS, lipopolysaccharide; TLR, Toll-like receptor; CD, cluster of differentiation; HSP, heat shock protein; NADPH, nicotinamide adenine dinucleotide phosphate; NOX, NADPH oxidase; MDA, malondialdehyde; ROS, reactive oxygen species; NK-cell, natural killer cell; IL, interleukin; TNF, tumor necrosis factor; MCP-5, monocyte chemotactic protein 5; MIP, macrophage inflammatory protein; INF, interferon; NO, nitric oxide.

and protein oxidation (134) leading to the loss of membrane integrity, structural and functional changes in proteins, and gene mutations (135). ROS and RNS are considered to be the most important liver toxicity mechanisms resulting from cell damage. The sub-gingival dental plaque is the main etiological agent for the initiation of inflammatory changes in the periodontal tissue and the cell component of bacteria, which exists in the dental plaque and recruits and activates hyper responsive polymorphonucleocytes, thus accelerating the process of ROS production.

Periodontitis and ROS. Various studies have demonstrated the effect of periodontitis on circulating ROS and oxidative stress. For example, thiobarbituric acid reactive substances, such as malondialdehyde (MDA), a biomarker commonly employed for lipid peroxidation, the levels of which are elevated, systemically, in plasma, in erythrocytes and locally in tissue homogenates, in patients with periodontitis $(136,137)$. MDA was also found to be raised in the gingival crevicular fluid (GCF) and saliva of patients with periodontitis, as compared to healthy controls. Furthermore, the GCF concentrations of MDA/4-hydroxyalkanal were 200- to 400-fold higher than the saliva concentrations, which reflected a substantially higher quantity of ROS activity in the GCF than the saliva (138). In a study where $P$. gingivalis-generated LPS (LPS-PG) stimulated PDL fibroblasts were established, the results demonstrated that nicotinamide adenine dinucleotide phosphate (NADPH) oxidase 4 (NOX4) levels significantly increased following hypoxic or inflammatory stimulation in PDL cells, and was accompanied by a significant upregulation of ROS and catalase (139). In a case-control study, lower levels of glutathione, catalase, and selenium were observed in the serum of patients with periodontitis when compared to those of the healthy control group and the difference was significant (140). Furthermore, it has been shown that periodontal treatment improves the circulating pro-oxidant/antioxidant balance in chronic periodontitis patients (141). In addition, studies have shown that non-surgical and surgical periodontal therapy was effective in reducing plasma ROMs (142-145). Based on these 
findings, it is proposed that periodontitis-induced ROS may be involved in liver injuries.

\section{Hypothesis}

Periodontitis and LD significantly impact health. The associations between periodontitis and NAFLD, LC, HCC, and LT have previously been investigated (Fig. 1). Certain pathological features are shared by periodontitis and systemic diseases, such as DM and CVDs, may exert similar effects on the liver. Among the three mechanisms (including bacteria, pro-inflammatory mediators and oxidative stress), various bacteria exist in the dental plaque, some of which are more dominant in patients with severe periodontitis, may significantly contribute to the linking of other pathological mechanisms (Fig. 2). Although periodontitis is a common disease, in the majority of cases, it can be prevented and cured. However, due to the fact that compared with other life-threatening diseases, such as LC and CVDs, periodontitis seems relatively harmless, it is common for patients with severe LD to neglect to their oral hygiene, even when they present with periodontitis. This phenomenon is not limited to patients; doctors also neglect the potential damage caused by periodontitis to the liver. The aim of the current review was to highlight the association between periodontitis and LD, in the hope that individuals who suffer from LD will attend to their periodontal health and, by employing simple dental health strategies, improve their liver condition.

In addition, all of the studies conducted thus far have ruled out viral hepatitis despite its high prevalence; with $350-400$ million cases of chronic HBV infection $(146,147)$ and 170 million cases of HCV infection (148) worldwide. Furthermore, dentists are associated with a greater (3- to 6-times) chance of HBV infection than the general population, which is the highest rate of $\mathrm{HBV}$ infection among all healthcare workers (149). The risk of HCV transmission and cross contamination within dental practices has previously been reported (150). It is hypothesized that by administering dental care to patients with viral hepatitis in a more central manner, for example, by establishing a specific dental care facility exclusively for those patients may be beneficial to dentists and patients. Therefore, further investigations are required to investigate the potential effect of periodontitis on viral hepatitis, and increased collaborations between physicians and dentists are strongly advised.

\section{References}

1. Vos T, Flaxman AD, Naghavi M,Lozano R, Michaud C, Ezzati M Shibuya K, Salomon JA, Abdalla S, Aboyans V, et al: Years lived with disability (YLDs) for 1160 sequelae of 289 diseases and injuries 1990-2010: a systematic analysis for the Global Burden of Disease Study 2010. Lancet 380: 2163-2196, 2012.

2. Chung JH, Hwang HJ, Kim SH and Kim TH: Associations Between Periodontitis and Chronic Obstructive Pulmonary Disease; the 2010-2012 Korean National Health and Nutrition Examination Survey (KNHANES). J Periodontol: Feb 25, 2016 (Epub ahead of print).

3. O'Dowd LK, Durham J, McCracken GI and Preshaw PM: Patients' experiences of the impact of periodontal disease. J Clin Periodontol 37: 334-339, 2010.

4. Gurav AN: The association of periodontitis and metabolic syndrome. Dent Res J (Isfahan) 11: 1-10, 2014.

5. Offenbacher S: Periodontal diseases: Pathogenesis. Ann Periodontol 1: 821-878, 1996.
6. Mealey BL and Rethman MP: Periodontal disease and diabetes mellitus. Bidirectional relationship. Dent Today 22: 107-113, 2003.

7. Collin HL, Uusitupa M, Niskanen L, Kontturi-Närhi V Markkanen H, Koivisto AM and Meurman JH: Periodontal findings in elderly patients with non-insulin dependent diabetes mellitus. J Periodontol 69: 962-966, 1998.

8. Murray CJ and Lopez AD: Mortality by cause for eight regions of the world: Global Burden of Disease Study. Lancet 349: 1269-1276, 1997.

9. Kuo LC, Polson AM and Kang T: Associations between periodontal diseases and systemic diseases: A review of the inter-relationships and interactions with diabetes, respiratory diseases, cardiovascular diseases and osteoporosis. Public Health 122: 417-433, 2008.

10. Scannapieco FA: Role of oral bacteria in respiratory infection. J Periodontol 70: 793-802, 1999.

11. No authors listed: The World Health Report 1997 - conquering suffering, enriching humanity. World Health Forum 18: 248-260, 1997.

12. Dave S, Batista EL Jr and Van Dyke TE: Cardiovascular disease and periodontal diseases: Commonality and causation. Compend Contin Educ Dent 25 (Suppl 1): 26-37, 2004.

13. Reddy MS: Osteoporosis and periodontitis: Discussion, conclusions, and recommendations. Ann Periodontol 6: 214-217, 2001.

14. Aspalli SS, Shetty VS, Parab PG, Nagappa G, Devnoorkar A and Devarathnamma MV: Osteoporosis and periodontitis: Is there a possible link? Indian J Dent Res 25: 316-20, 2014.

15. Angulo P: Nonalcoholic fatty liver disease. N Engl J Med 346: 1221-1231, 2002

16. Milić S and Stimac D: Nonalcoholic fatty liver disease/steatohepatitis: Epidemiology, pathogenesis, clinical presentation and treatment. Dig Dis 30: 158-162, 2012.

17. Angulo P and Lindor KD: Non-alcoholic fatty liver disease. J Gastroenterol Hepatol 17: S186-S190, 2002.

18. Liou I and Kowdley KV: Natural history of nonalcoholic steatohepatitis. J Clin Gastroenterol 40 (Suppl 1): S11-S16, 2006.

19. Oh HJ, Kim TH, Sohn YW, Kim YS, Oh YR, Cho EY, Shim SY, Shin SR, Han AL, Yoon SJ, et al: Association of serum alanine aminotransferase and $\gamma$-glutamyltransferase levels within the reference range with metabolic syndrome and nonalcoholic fatty liver disease. Korean J Hepatol 17: 27-36, 2011.

20. Adams LA, Knuiman MW, Divitini ML and Olynyk JK: Body mass index is a stronger predictor of alanine aminotransaminase levels than alcohol consumption. J Gastroenterol Hepatol 23: 1089-1093, 2008.

21. Furuta M, Ekuni D, Yamamoto T, Irie K, Koyama R, Sanbe T, Yamanaka R, Morita M, Kuroki K and Tobe K: Relationship between periodontitis and hepatic abnormalities in young adults. Acta Odontol Scand 68: 27-33, 2010.

22. Saito T, Shimazaki Y, Koga T, Tsuzuki M and Ohshima A: Relationship between periodontitis and hepatic condition in Japanese women. J Int Acad Periodontol 8: 89-95, 2006.

23. Morita T, Yamazaki Y, Fujiharu C, Ishii T, Seto M, Nishinoue N, Sasaki Y, Kawato T, Motohashi M and Maeno M: Serum $\gamma$-glutamyltransferase level is associated with periodontal disease independent of drinking habits in Japanese adults. Med Sci Monit 20: 2109-2116, 2014

24. Yoneda M, Naka S, Nakano K, Wada K, Endo H, Mawatari H, Imajo K, Nomura R, Hokamura K, Ono M, et al: Involvement of a periodontal pathogen, Porphyromonas gingivalis on the pathogenesis of non-alcoholic fatty liver disease. BMC Gastroenterol 12: 16, 2012.

25. Friedman SL: Mechanisms of hepatic fibrogenesis. Gastroenterology 134: 1655-1669, 2008.

26. Zhang DY and Friedman SL: Fibrosis-dependent mechanisms of hepatocarcinogenesis. Hepatology 56: 769-775, 2012.

27. Murray KF and Carithers RL Jr; AASLD: AASLD practice guidelines: Evaluation of the patient for liver transplantation. Hepatology 41: 1407-1432, 2005.

28. Novacek G, Plachetzky U, Pötzi R, Lentner S, Slavicek R, Gangl A and Ferenci P: Dental and periodontal disease in patients with cirrhosis - role of etiology of liver disease. J Hepatol 22: 576-582, 1995

29. Sponholz H, Naethbohm K, Brügmann E and Maass M: Correlations between chronic liver diseases and periodontal diseases with special reference to animal experiments. Stomatol DDR 26: 409-413, 1976 (In German).

30. Movin S: Relationship between periodontal disease and cirrhosis of the liver in humans. J Clin Periodontol 8: 450-458, 1981. 
31. Funatsu K, Yamada M, Kawishima Y, Nishida J, Ueno M, Ebihara Y, Mizuno Y, Oda M and Tsuchiya M: Microcirculatory disturbances of oral mucosa and periodontal disease in patients with liver cirrhosis. J Gastroenterol Hepatol 4 (Suppl 1): 99-102, 1989.

32. Jaiswal G, Deo V, Bhongade M and Jaiswal S: Serum alkaline phosphatase: A potential marker in the progression of periodontal disease in cirrhosis patients. Quintessence Int 42: 345-348, 2011.

33. Ferlay J, Shin HR, Bray F, Forman D, Mathers C and Parkin DM: Estimates of worldwide burden of cancer in 2008: GLOBOCAN 2008. Int J Cancer 127: 2893-2917, 2010.

34. Bosch FX, Ribes J, Díaz M and Cléries R: Primary liver cancer: Worldwide incidence and trends. Gastroenterology 127 (Suppl 1): S5-S16, 2004.

35. Anzola M: Hepatocellular carcinoma: Role of hepatitis B and hepatitis $\mathrm{C}$ viruses proteins in hepatocarcinogenesis. J Viral Hepat 11: 383-393, 2004.

36. Fattovich G, Stroffolini T, Zagni I and Donato F: Hepatocellular carcinoma in cirrhosis: Incidence and risk factors. Gastroenterology 127 (Suppl 1): S35-S50, 2004.

37. Bralet MP, Régimbeau JM, Pineau P, Dubois S, Loas G, Degos F, Valla D, Belghiti J, Degott C and Terris B: Hepatocellular carcinoma occurring in nonfibrotic liver: Epidemiologic and histopathologic analysis of 80 French cases. Hepatology 32: 200-204, 2000.

38. Hujoel PP, Drangsholt M, Spiekerman C and Weiss NS: An exploration of the periodontitis-cancer association. Ann Epidemiol 13: 312-316, 2003

39. Tezal M, Sullivan MA, Reid ME, Marshall JR, Hyland A, Loree T, Lillis C, Hauck L, Wactawski-Wende J and Scannapieco FA: Chronic periodontitis and the risk of tongue cancer. Arch Otolaryngol Head Neck Surg 133: 450-454, 2007.

40. Tezal M, Sullivan MA, Hyland A, Marshall JR, Stoler D, Reid ME, Loree TR, Rigual NR, Merzianu M, Hauck L, et al: Chronic periodontitis and the incidence of head and neck squamous cell carcinoma. Cancer Epidemiol Biomarkers Prev 18: 2406-2412, 2009.

41. Kudo M, Chung H, Haji S, Osaki Y, Oka H, Seki T, Kasugai H, Sasaki Y and Matsunaga T: Validation of a new prognostic staging system for hepatocellular carcinoma: The JIS score compared with the CLIP score. Hepatology 40: 1396-1405, 2004.

42. Luo KZ, Itamoto T, Amano H, Oshita A, Ushitora Y, Tanimoto Y, Ohdan $\mathrm{H}$, Tashiro $\mathrm{H}$ and Asahara T: Comparative study of the Japan Integrated Stage (JIS) and modified JIS score as a predictor of survival after hepatectomy for hepatocellular carcinoma. J Gastroenterol 43: 369-377, 2008.

43. Pugh RN, Murray-Lyon IM, Dawson JL, Pietroni MC and Williams R: Transection of the oesophagus for bleeding oesophageal varices. Br J Surg 60: 646-649, 1973.

44. Tamaki N, Takaki A, Tomofuji T, Endo Y, Kasuyama K, Ekuni D, Yasunaka T, Yamamoto K and Morita M: Stage of hepatocellular carcinoma is associated with periodontitis. J Clin Periodontol 38: 1015-1020, 2011

45. Maggs JR, Suddle AR, Aluvihare V and Heneghan MA: Systematic review: The role of liver transplantation in the management of hepatocellular carcinoma. Aliment Pharmacol Ther 35: 1113-1134, 2012.

46. Penn I: Hepatic transplantation for primary and metastatic cancers of the liver. Surgery 110: 726-734, discussion 734-735, 1991.

47. Pichlmayr R, Weimann A and Ringe B: Indications for liver transplantation in hepatobiliary malignancy. Hepatology 20 (1 Pt 2): 33S-40S, 1994

48. Yao FY, Ferrell L, Bass NM, Watson JJ, Bacchetti P, Venook A, Ascher NL and Roberts JP: Liver transplantation for hepatocellular carcinoma: Expansion of the tumor size limits does not adversely impact survival. Hepatology 33: 1394-1403, 2001.

49. Mazzaferro V, Regalia E, Doci R, Andreola S, Pulvirenti A, Bozzetti F, Montalto F, Ammatuna M, Morabito A and Gennari L: Liver transplantation for the treatment of small hepatocellular carcinomas in patients with cirrhosis. N Engl J Med 334: 693-699, 1996

50. Guggenheimer J, Eghtesad B and Stock DJ: Dental management of the (solid) organ transplant patient. Oral Surg Oral Med Oral Pathol Oral Radiol Endod 95: 383-389, 2003.

51. Guggenheimer J, Mayher D and Eghtesad B: A survey of dental care protocols among US organ transplant centers. Clin Transplant 19: 15-18, 2005.

52. Guggenheimer J, Eghtesad B, Close JM, Shay C and Fung JJ: Dental health status of liver transplant candidates. Liver Transpl 13: 280-286, 2007.
53. Douglas LR, Douglass JB, Sieck JO and Smith PJ: Oral management of the patient with end-stage liver disease and the liver transplant patient. Oral Surg Oral Med Oral Pathol Oral Radiol Endod 86: 55-64, 1998

54. Little JW and Rhodus NL: Dental treatment of the liver transplant patient. Oral Surg Oral Med Oral Pathol 73: 419-426, 1992.

55. Rustemeyer J and Bremerich A: Necessity of surgical dental foci treatment prior to organ transplantation and heart valve replacement. Clin Oral Investig 11: 171-174, 2007.

56. Silva Santos PS, Fernandes KS and Gallottini MH: Assessment and management of oral health in liver transplant candidates. J Appl Oral Sci 20: 241-245, 2012.

57. Aberg F, Helenius-Hietala J, Meurman J and Isoniemi H: Association between dental infections and the clinical course of chronic liver disease. Hepatol Res 44: 349-353, 2014.

58. Helenius-Hietala J, Meurman JH, Höckerstedt K, Lindqvist C and Isoniemi $\mathrm{H}$ : Effect of the aetiology and severity of liver disease on oral health and dental treatment prior to transplantation. Transpl Int 25: 158-165, 2012.

59. Bader G, Mesner M and Lejeune S: Oral surgery for liver transplant patients. Oral Surg Oral Med Oral Pathol Oral Radiol Endod 84: 593, 1997.

60. Golla K, Epstein JB and Cabay RJ: Liver disease: Current perspectives on medical and dental management. Oral Surg Oral Med Oral Pathol Oral Radiol Endod 98: 516-521, 2004.

61. Valerin MA, Napeñas JJ, Brennan MT, Fox PC and Lockhart PB: Modified Child-Pugh score as a marker for postoperative bleeding from invasive dental procedures. Oral Surg Oral Med Oral Pathol Oral Radiol Endod 104: 56-60, 2007.

62. Ward BB and Weideman EM: Long-term postoperative bleeding after dentoalveolar surgery in the pretransplant liver failure patient. J Oral Maxillofac Surg 64: 1469-1474, 2006.

63. Lins L, Bittencourt PL, Evangelista MA, Lins R, Codes L, Cavalcanti AR, Paraná R and Bastos J: Oral health profile of cirrhotic patients awaiting liver transplantation in the Brazilian Northeast. Transplant Proc 43: 1319-1321, 2011.

64. Sheehy EC, Roberts GJ, Beighton D and O'Brien G: Oral health in children undergoing liver transplantation. Int J Paediatr Dent 10: 109-119, 2000

65. Barbero P, Garzino Demo MG, Milanesio M and Ottobrelli A: The dental assessment of the patient waiting for a liver transplant. Minerva Stomatol 45: 431-439, 1996 (In Italian).

66. Kumar PS, Griffen AL, Barton JA, Paster BJ, Moeschberger ML and Leys EJ: New bacterial species associated with chronic periodontitis. J Dent Res 82: 338-344, 2003

67. Kumar PS, Griffen AL, Moeschberger ML and Leys EJ: Identification of candidate periodontal pathogens and beneficial species by quantitative $16 \mathrm{~S}$ clonal analysis. J Clin Microbiol 43 3944-3955, 2005.

68. Fernández J and Gustot T: Management of bacterial infections in cirrhosis. J Hepatol 56 (Suppl 1): S1-S12, 2012.

69. Gustot T, Durand F, Lebrec D, Vincent JL and Moreau R: Severe sepsis in cirrhosis. Hepatology 50: 2022-2033, 2009.

70. Fernández J, Navasa M, Gómez J, Colmenero J, Vila J, Arroyo V and Rodés J: Bacterial infections in cirrhosis: Epidemiological changes with invasive procedures and norfloxacin prophylaxis. Hepatology 35: 140-148, 2002.

71. Fernández J, Acevedo J, Castro M, Garcia O, de Lope CR, Roca D, Pavesi M, Sola E, Moreira L, Silva A, et al: Prevalence and risk factors of infections by multiresistant bacteria in cirrhosis: A prospective study. Hepatology 55: 1551-1561, 2012.

72. Fagiuoli S, Colli A, Bruno R, Craxì A, Gaeta GB, Grossi P, Mondelli MU, Puoti M, Sagnelli E, Stefani S, et al; 2011 AISF Single Topic Group: Management of infections pre- and post-liver transplantation: Report of an AISF consensus conference. J Hepatol 60: 1075-1089, 2014.

73. Yilmaz O: The chronicles of Porphyromonas gingivalis: The microbium, the human oral epithelium and their interplay. Microbiology 154: 2897-2903, 2008.

74. Scannapieco FA, Bush RB and Paju S: Associations between periodontal disease and risk for atherosclerosis, cardiovascular disease, and stroke. A systematic review. Ann Periodontol 8: 38-53, 2003.

75. Beck J, Garcia R, Heiss G, Vokonas PS and Offenbacher S Periodontal disease and cardiovascular disease. J Periodontol 67 (Suppl 10): 1123-1137, 1996.

76. Boggess KA, Madianos PN, Preisser JS, Moise KJ Jr and Offenbacher S: Chronic maternal and fetal Porphyromonas gingivalis exposure during pregnancy in rabbits. Am J Obstet Gynecol 192: 554-557, 2005. 
77. Furusho H, Miyauchi M, Hyogo H, Inubushi $\mathrm{T}$, Ao $\mathrm{M}$ Ouhara K, Hisatune J, Kurihara $\mathrm{H}$, Sugai M, Hayes CN, et al: Dental infection of Porphyromonas gingivalis exacerbates high fat diet-induced steatohepatitis in mice. J Gastroenterol 48: 1259-1270, 2013

78. Raja M, Ummer F and Dhivakar CP: Aggregatibacter actinomycetemcomitans - a tooth killer? J Clin Diagn Res 8: ZE13-ZE16, 2014.

79. Narayanan SK, Nagaraja TG, Chengappa MM and Stewart GC: Leukotoxins of gram-negative bacteria. Vet Microbiol 84 337-356, 2002.

80. Chen PB, Davern LB, Neiders ME, Reynolds HS and Zambon JJ: Analysis of in vitro lymphoproliferative responses and antibody formation following subcutaneous injection of Actinobacillus actinomycetemcomitans and Wolinella recta in a murine model. Oral Microbiol Immunol 6: 12-16, 1991.

81. Tuomainen AM, Jauhiainen M, Kovanen PT, Metso J, Paju S and Pussinen PJ: Aggregatibacter actinomycetemcomitans induces MMP-9 expression and proatherogenic lipoprotein profile in apoE-deficient mice. Microb Pathog 44: 111-117, 2008.

82. Hyvärinen K, Tuomainen AM, Laitinen S, Bykov IL, Törmäkangas L, Lindros K, Käkelä R, Alfthan G, Salminen I, Jauhiainen M, et al: Chlamydial and periodontal pathogens induce hepatic inflammation and fatty acid imbalance in apolipoprotein E-deficient mice. Infect Immun 77: 3442-3449, 2009.

83. Qin N, Yang F, Li A, Prifti E, Chen Y, Shao L, Guo J, Le Chatelier E, Yao J, Wu L, et al: Alterations of the human gut microbiome in liver cirrhosis. Nature 513: 59-64, 2014.

84. Goel A, Gupta M and Aggarwal R: Gut microbiota and liver disease. J Gastroenterol Hepatol 29: 1139-1148, 2014.

85. Yoshimoto S, Loo TM, Atarashi K, Kanda H, Sato S, Oyadomari S, Iwakura Y, Oshima K, Morita H, Hattori M, et al: Obesity-induced gut microbial metabolite promotes liver cancer through senescence secretome. Nature 499: 97-101, 2013.

86. Wiest R, Lawson M and Geuking M: Pathological bacterial translocation in liver cirrhosis. J Hepatol 60: 197-209, 2014.

87. DiBaise JK, Zhang H, Crowell MD, Krajmalnik-Brown R, Decker GA and Rittmann BE: Gut microbiota and its possible relationship with obesity. Mayo Clin Proc 83: 460-469, 2008.

88. Socransky SS and Haffajee AD: Periodontal microbial ecology. Periodontol 2000 38: 135-187, 2005.

89. Goodson JM, Groppo D, Halem S and Carpino E: Is obesity an oral bacterial disease? J Dent Res 88: 519-523, 2009.

90. Boutaga K, Savelkoul PH, Winkel EG and van Winkelhoff AJ Comparison of subgingival bacterial sampling with oral lavage for detection and quantification of periodontal pathogens by real-time polymerase chain reaction. J Periodontol 78: 79-86, 2007.

91. Saygun I, Nizam N, Keskiner I, Bal V, Kubar A, Açıkel C, Serdar M and Slots J: Salivary infectious agents and periodontal disease status. J Periodontal Res 46: 235-239, 2011.

92. von Troil-Lindén B, Torkko H, Alaluusua S, Jousimies-Somer H and Asikainen S: Salivary levels of suspected periodontal pathogens in relation to periodontal status and treatment. J Dent Res 74: 1789-1795, 1995.

93. Koren O, Spor A, Felin J, Fåk F, Stombaugh J, Tremaroli V, Behre CJ, Knight R, Fagerberg B, Ley RE, et al: Human oral, gut, and plaque microbiota in patients with atherosclerosis. Proc Natl Acad Sci USA 108 (Suppl 1): 4592-4598, 2011.

94. O'Toole PW and Cooney JC: Probiotic bacteria influence the composition and function of the intestinal microbiota. Interdiscip Perspect Infect Dis 2008: 175285, 2008

95.Lentsch AB, Yoshidome H, Kato A, Warner RL, Cheadle WG, Ward PA and Edwards MJ: Requirement for interleukin-12 in the pathogenesis of warm hepatic ischemia/reperfusion injury in mice. Hepatology 30: 1448-1453, 1999.

96.Lentsch AB, Yoshidome H, Cheadle WG, Miller FN and Edwards MJ: Chemokine involvement in hepatic ischemia/reperfusion injury in mice: Roles for macrophage inflammatory protein-2 and KC. Hepatology 27: 1172-1177, 1998.

97. Gandoura S, Weiss E, Rautou PE, Fasseu M, Gustot T, Lemoine F, Hurtado-Nedelec M, Hego C, Vadrot N, Elkrief L, et al: Gene- and exon-expression profiling reveals an extensive LPS-induced response in immune cells in patients with cirrhosis. J Hepatol 58: 936-948, 2013.

98. Coant N, Simon-Rudler M, Gustot T, Fasseu M, Gandoura S, Ragot K, Abdel-Razek W, Thabut D, Lettéron P, Ogier-Denis E, et al: Glycogen synthase kinase 3 involvement in the excessive proinflammatory response to LPS in patients with decompensated cirrhosis. J Hepatol 55: 784-793, 2011.
99. Tazi KA, Quioc JJ, Saada V, Bezeaud A, Lebrec D and Moreau R Upregulation of TNF-alpha production signaling pathways in monocytes from patients with advanced cirrhosis: Possible role of Akt and IRAK-M. J Hepatol 45: 280-289, 2006.

100. Galbois A, Thabut D, Tazi KA, Rudler M, Mohammadi MS, Bonnefont-Rousselot D, Bennani H, Bezeaud A, Tellier Z, Guichard C, et al: Ex vivo effects of high-density lipoprotein exposure on the lipopolysaccharide-induced inflammatory response in patients with severe cirrhosis. Hepatology 49: 175-184, 2009

101. Thabut D, Massard J, Gangloff A, Carbonell N, Francoz C, Nguyen-Khac E, Duhamel C, Lebrec D, Poynard T and Moreau R: Model for end-stage liver disease score and systemic inflammatory response are major prognostic factors in patients with cirrhosis and acute functional renal failure. Hepatology 46: 1872-1882, 2007.

102. Byl B, Roucloux I, Crusiaux A, Dupont E and Devière J: Tumor necrosis factor alpha and interleukin 6 plasma levels in infected cirrhotic patients. Gastroenterology 104: 1492-1497, 1993.

103. Navasa M, Follo A, Filella X, Jiménez W, Francitorra A, Planas R, Rimola A, Arroyo V and Rodés J: Tumor necrosis factor and interleukin-6 in spontaneous bacterial peritonitis in cirrhosis: Relationship with the development of renal impairment and mortality. Hepatology 27: 1227-1232, 1998.

104. Devière J, Content J, Denys C, Vandenbussche P, Schandene L, Wybran $J$ and Dupont E: Excessive in vitro bacterial lipopolysaccharide-induced production of monokines in cirrhosis. Hepatology 11: 628-634, 1990

105. Le Moine O, Marchant A, De Groote D, Azar C, Goldman M and Devière J: Role of defective monocyte interleukin-10 release in tumor necrosis factor-alpha overproduction in alcoholics cirrhosis. Hepatology 22: 1436-1439, 1995.

106. Moreau R, Barrière E, Tazi KA, Lardeux B, Dargère D, Urbanowicz W, Poirel O, Chauvelot-Moachon L, Guimont MC, Bernuau D, et al: Terlipressin inhibits in vivo aortic iNOS expression induced by lipopolysaccharide in rats with biliary cirrhosis. Hepatology 36: 1070-1078, 2002.

107. Tazi KA, Bièche I, Paradis V, Guichard C, Laurendeau I, Dargère D, Legrand A, Fay M, Pedruzzi E, Robin MA, et al: In vivo altered unfolded protein response and apoptosis in livers from lipopolysaccharide-challenged cirrhotic rats. J Hepatol 46: 1075-1088, 2007.

108. Thabut D, Tazi KA, Bonnefont-Rousselot D, Aller M, Farges O, Guimont MC, Tellier Z, Guichard C, Ogier-Denis E, Poynard T, et al: High-density lipoprotein administration attenuates liver proinflammatory response, restores liver endothelial nitric oxide synthase activity, and lowers portal pressure in cirrhotic rats. Hepatology 46: 1893-1906, 2007.

109. Abu-Shanab A and Quigley EM: The role of the gut microbiota in nonalcoholic fatty liver disease. Nat Rev Gastroenterol Hepatol 7: 691-701, 2010.

110. Madianos PN, Bobetsis YA and Kinane DF: Generation of inflammatory stimuli: How bacteria set up inflammatory responses in the gingiva. J Clin Periodontol 32 (Suppl 6): 57-71, 2005.

111. Shapira L, Champagne C, Van Dyke TE and Amar S: Strain-dependent activation of monocytes and inflammatory macrophages by lipopolysaccharide of Porphyromonas gingivalis. Infect Immun 66: 2736-2742, 1998.

112. Hirschfeld M, Weis JJ, Toshchakov V, Salkowski CA, Cody MJ, Ward DC, Qureshi N, Michalek SM and Vogel SN: Signaling by toll-like receptor 2 and 4 agonists results in differential gene expression in murine macrophages. Infect Immun 69: 1477-1482, 2001.

113. Malik R, Mookerjee RP and Jalan R: Infection and inflammation in liver failure: Two sides of the same coin. J Hepatol 51: 426-429, 2009.

114. Tritto G, Bechlis Z, Stadlbauer V, Davies N, Francés R, Shah N, Mookerjee RP, Such J and Jalan R: Evidence of neutrophil functional defect despite inflammation in stable cirrhosis. J Hepatol 55: 574-581, 2011.

115. Tilg $\mathrm{H}$ and Moschen AR: IL-1 cytokine family members and NAFLD: Neglected in metabolic liver inflammation. J Hepatol 55: 960-962, 2011.

116. Muñoz NM, Katz LH, Shina JH, Gi YJ, Menon VK, Gagea M, Rashid A, Chen J and Mishra L: Generation of a mouse model of T-cell lymphoma based on chronic LPS challenge and TGF- $\beta$ signaling disruption. Genes Cancer 5: 348-352, 2014.

117. Su GL, Klein RD, Aminlari A, Zhang HY, Steinstraesser L, Alarcon WH, Remick DG and Wang SC: Kupffer cell activation by lipopolysaccharide in rats: Role for lipopolysaccharide binding protein and toll-like receptor 4. Hepatology 31: 932-936, 2000. 
118. Baffy G: Kupffer cells in non-alcoholic fatty liver disease: The emerging view. J Hepatol 51: 212-223, 2009.

119. Honda Y, Yamagiwa S, Matsuda Y, Takamura M, Ichida T and Aoyagi Y: Altered expression of TLR homolog RP105 on monocytes hypersensitive to LPS in patients with primary biliary cirrhosis. J Hepatol 47: 404-411, 2007.

120. Yang SQ, Lin HZ, Lane MD, Clemens M and Diehl AM: Obesity increases sensitivity to endotoxin liver injury: Implications for the pathogenesis of steatohepatitis. Proc Natl Acad Sci USA 94: 2557-2562, 1997.

121. Miura K, Yang L, van Rooijen N, Brenner DA, Ohnishi H and Seki E: Toll-like receptor 2 and palmitic acid cooperatively contribute to the development of nonalcoholic steatohepatitis through inflammasome activation in mice. Hepatology 57: 577-589, 2013.

122. Medzhitov R: Toll-like receptors and innate immunity. Nat Rev Immunol 1: 135-145, 2001.

123. Mattsson E, Verhage L, Rollof J, Fleer A, Verhoef J and van Dijk H: Peptidoglycan and teichoic acid from Staphylococcus epidermidis stimulate human monocytes to release tumour necrosis factor-alpha, interleukin-1 beta and interleukin-6. FEMS Immunol Med Microbiol 7: 281-287, 1993.

124. Wang ZM, Liu C and Dziarski R: Chemokines are the main proinflammatory mediators in human monocytes activated by Staphylococcus aureus, peptidoglycan, and endotoxin. J Biol Chem 275: 20260-20267, 2000.

125. Kengatharan KM, De Kimpe S, Robson C, Foster SJ and Thiemermann C: Mechanism of gram-positive shock: Identification of peptidoglycan and lipoteichoic acid moieties essential in the induction of nitric oxide synthase, shock, and multiple organ failure. J Exp Med 188: 305-315, 1998.

126. Forner L, Nielsen CH, Bendtzen K, Larsen T and Holmstrup P: Increased plasma levels of IL-6 in bacteremic periodontis patients after scaling. J Clin Periodontol 33: 724-729, 2006.

127.Loos BG, Craandijk J, Hoek FJ, Wertheim-van Dillen PM and van der Velden U: Elevation of systemic markers related to cardiovascular diseases in the peripheral blood of periodontitis patients. J Periodontol 71: 1528-1534, 2000.

128. Morré SA, Ouburg S, Klinkenberg-Knol EC, Mulder CJ and Peña AS: The true ligand of the NOD 2 receptor is peptidoglycan instead of lipopolysaccharide: A schematic representation of ligand-receptor interactions and NF-kappa B activation. Gastroenterology 126: 371-373, 2004.

129. Lichtman SN, Wang J, Schwab JH and Lemasters JJ: Comparison of peptidoglycan-polysaccharide and lipopolysaccharide stimulation of Kupffer cells to produce tumor necrosis factor and interleukin-1. Hepatology 19: 1013-1022, 1994.

130. Petit MD, Wassenaar A, van der Velden U, van Eden W and Loos BG: Depressed responsiveness of peripheral blood mononuclear cells to heat-shock proteins in periodontitis patients. J Dent Res 78: 1393-1400, 1999.

131. Tabeta K, Yamazaki K, Hotokezaka H, Yoshie H and Hara K: Elevated humoral immune response to heat shock protein 60 (hsp60) family in periodontitis patients. Clin Exp Immunol 120: 285-293, 2000.

132. Wick G: Atherosclerosis - an autoimmune disease due to an immune reaction against heat-shock protein 60. Herz 25: 87-90, 2000.

133. Yamazaki K, Ohsawa Y, Tabeta K, Ito H, Ueki K, Oda T, Yoshie H and Seymour GJ: Accumulation of human heat shock protein 60 -reactive $\mathrm{T}$ cells in the gingival tissues of periodontitis patients. Infect Immun 70: 2492-2501, 2002.

134. Nencini C, Giorgi G and Micheli L: Protective effect of silymarin on oxidative stress in rat brain. Phytomedicine 14: 129-135, 2007.

135.Reddy BV, Sundari JS, Balamurugan E and Menon VP: Prevention of nicotine and streptozotocin treatment induced circulatory oxidative stress by bis-1,7-(2-hydroxyphenyl)-hept a-1,6-diene-3,5-dione in diabetic rats. Mol Cell Biochem 331: $127-133,2009$.
136. Tüter G, Kurtis B and Serdar M: Interleukin-1beta and thiobarbituric acid reactive substance (TBARS) levels after phase I periodontal therapy in patients with chronic periodontitis. J Periodontol 72: 883-888, 2001.

137. Tsai CC, Chen HS, Chen SL, Ho YP, Ho KY, Wu YM and Hung CC: Lipid peroxidation: A possible role in the induction and progression of chronic periodontitis. J Periodontal Res 40: 378-384, 2005.

138. Akalin FA, Baltacioğlu E, Alver A and Karabulut E: Lipid peroxidation levels and total oxidant status in serum, saliva and gingival crevicular fluid in patients with chronic periodontitis. J Clin Periodontol 34: 558-565, 2007.

139. Golz L, Memmert S, Rath-Deschner B, Jager A, Appel T, Baumgarten G, Götz W and Frede S: LPS from P. gingivalis and hypoxia increases oxidative stress in periodontal ligament fibroblasts and contributes to periodontitis. Mediators Inflamm 2014: 986264, 2014.

140. Thomas B, Ramesh A, Suresh S and Prasad BR: A comparative evaluation of antioxidant enzymes and selenium in the serum of periodontitis patients with diabetes mellitus type 2 . Contemp Clin Dent 4: 176-180, 2013.

141. Tamaki N, Tomofuji T, Ekuni D, Yamanaka R and Morita M: Periodontal treatment decreases plasma oxidized LDL level and oxidative stress. Clin Oral Investig 15: 953-958, 2011.

142. D'Aiuto F, Nibali L, Parkar M, Patel K, Suvan J and Donos N: Oxidative stress, systemic inflammation, and severe periodontitis. J Dent Res 89: 1241-1246, 2010.

143. Tamaki N, Tomofuji T, Ekuni D, Yamanaka R, Yamamoto T and Morita M: Short-term effects of non-surgical periodontal treatment on plasma level of reactive oxygen metabolites in patients with chronic periodontitis. J Periodontol 80: 901-906, 2009.

144. Chaudhary S, Gowda TM, Mehta DS and Kumar TAB: Comparative evaluation of plasma ROM levels in chronic periodontitis patients before and after non-surgical and surgical periodontal therapy: A clinical trial. J Indian Soc Periodontol 18: 140-144, 2014

145. Wei D, Zhang XL, Wang YZ, Yang CX and Chen G: Lipid peroxidation levels, total oxidant status and superoxide dismutase in serum, saliva and gingival crevicular fluid in chronic periodontitis patients before and after periodontal therapy. Aust Dent J 55: 70-78, 2010.

146.Zacharakis G, Koskinas J, Kotsiou S, Tzara F, Vafeiadis N, Papoutselis M, Maltezos E, Sivridis E and Papoutselis K: The role of serial measurement of serum HBV DNA levels in patients with chronic $\mathrm{HBeAg}(-)$ hepatitis B infection: Association with liver disease progression. A prospective cohort study. J Hepatol 49: 884-891, 2008.

147. van Zonneveld M, Honkoop P, Hansen BE, Niesters HG, Darwish Murad S, de Man RA, Schalm SW and Janssen HL: Long-term follow-up of alpha-interferon treatment of patients with chronic hepatitis B. Hepatology 39: 804-810, 2004.

148. El-Serag HB: Epidemiology of viral hepatitis and hepatocellular carcinoma. Gastroenterology 142: 1264-1273.e1, 2012.

149. Alavian SM, Izadi M, Zare AA, Lankarani MM, Assari S and Vardi MM: Survey of the level of anti-HBs antibody titer in vaccinated Iranian general dentists. Spec Care Dentist 28: 265-270, 2008.

150. Mahboobi N, Porter SR, Karayiannis P and Alavian SM: Dental treatment as a risk factor for hepatitis $\mathrm{B}$ and $\mathrm{C}$ viral infection. A review of the recent literature. J Gastrointestin Liver Dis 22: 79-86, 2013. 